\title{
Information for actuaries valuing Periodical Payment Orders
}

\section{Abstract of the London Discussion}

[Institute and Faculty of Actuaries, Sessional Research Event, London, 28 June 2016]

This abstract relates to the following paper: The Institute and Faculty of Actuaries Periodical Payment Orders Working Party. Information for actuaries valuing Periodical Payment Orders. British Actuarial Journal. doi: 10.1017/S1357321717000101

The Chair (Mrs S. A. Dreksler, F.I.A.): This is a very important topic at the moment for general insurers, motor insurers and liability insurers: Periodical Payment Orders (PPOs) and how we deal with them, both in reserving and pricing.

The purpose of the discussion is to present a paper that is not quite finished. The working party are very keen to get your response to the paper as it stands at the moment, to collect your views and make sure that they make the final touches and make it the best paper it possibly can be.

We would also like others in the profession to think about what we ought to be doing around the issue of PPOs. There are quite interesting issues around our responsibility in the public interest and whether we ought to be doing more within the Institute and Faculty of Actuaries (IFoA) to raise some of the issues around PPOs that may not have come out to date. It will be really good to obtain lots of views on what we, as a profession, should be doing in terms of raising awareness of the issues around PPOs and not just how we deal with them within the companies for which we work.

The opener for the session, Peter Saunders, has been chair of the PPO working party since 2014, having been the deputy chair for 2 years prior to that, and a founding member in 2009. He has been involved in all of the papers that have been presented by the working party to date and he has presented several times before.

He is also a member of the General Insurance (GI) standards and consultations committee.

In his working life, he is a casualty underwriter and senior pricing actuary at Swiss Re, responsible for the production of UK motor benchmarks. He is responsible for global and international business. Peter has worked for Swiss Re for 12 years now, both in reserving and pricing. He has worked on PPOs in both capacities.

Prior to this, Peter worked for Tindall Riley, focussing on Professional Indemnity and Protection and Indemnity in respect of the management of the Britannia Steamship Insurance Association.

Mr P. J. Saunders, F.I.A. (introducing the paper): I should like to thank everybody on the working party. It has been a pleasure to be a part of it and also a pleasure to chair. I have really enjoyed the interactions that we have had. Everyone in the working party has made it so. 
We have three aims of our presentation. The first of those aims is to inform you about the information paper that we are producing. The second of those aims is to obtain feedback on the paper to try to steer the paper in the right direction so that it is the best possible resource for the actuarial profession. The third thing is to try and highlight some of the issues that we have come across in discussions with people, but also in thinking about how we can develop the paper such that we make sure that the profession is looking after its own interests and the interests of all of the stakeholders involved in PPOs.

We cannot guarantee everyone here knows everything about PPOs, or knows about PPOs at all, so there is going to be a brief introduction.

As an introduction, many of you are probably aware that, prior to the implementation of PPOs, compensation as a form of continuing payment was available back as far as 1989 by way of a structured settlement. These actions were rarely used at the time, perhaps because it required the agreement of both parties to settle on one.

The Courts Act 2003 introduced PPOs, and that was implemented in 2005. From that point, judges had the requirement to consider whether a PPO was an appropriate method of compensation in a certain number of cases.

From that point also, because of claims settling as a PPO, we saw a transfer of risk from the claimant to the insurer. The risk that the claimant had in the past was, of course, that they risked running out of money from the lump-sum settlement. They transferred that risk to the insurer by way of the insurer paying more than they would have done previously.

This creates difficulties for insurers and reinsurers alike that they had not previously seen, particularly as a significant number of insurers are GI focussed and will have had little or no experience of the life characteristics that these liabilities produce.

There are a number of issues and I think, probably, most of us are significantly aware of them. The working party was started in 2009 as a result of like-minded individuals seeing an increase in claims settlements for their companies.

The scope of the working party was twofold: it focussed on motoring liabilities; but what we really wanted to do was inform actuaries about the issues around PPOs and help them in terms of valuing them in their day jobs. We have produced a large number of outputs throughout the time, a number of reports, and delivered a number of presentations including trying to highlight some of the emerging issues, such as Ogden discount rate consultations.

One of the key things that people have looked at from our presentations is the proportion of large claims that are settling as a PPO. Historically, we have seen that between $30 \%$ and $40 \%$ of claims that are above $£ 1$ million in 2011 terms, have been settling as a PPO. We have reported, and discussed elsewhere, that there has been a reduction in the past year.

The working party are a group made up of a number of individuals from a wide range of companies. We cover all facets of GI work and have a significant number of participants in the working party that have life and health experience. 
The information paper we are producing is intended to help actuaries that are new to the topic obtain a good understanding of how they need to value these claims, and how they need to prepare their companies for the risks that they are taking. It is intended to help those more experienced with PPOs give some additional thoughts and, maybe, make them think about them in a different way. There may be actuaries who will be able to use the working party report to give them extra credibility when talking to their boards.

One thing that we are not trying to do is produce any guidance. Given we are not producing any guidance, clearly we could not produce a prescriptive paper. We could not produce a paper that would tell every actuary what they should be doing in each situation because there are just too many situations and we would get it wrong. So we have tried to create a paper which enables someone to think through the issues for themselves, think through what their situation is and to think what is the right situation and the right approach for that company.

There are a number of other things at which we are looking. We are hoping to do something on mortality, but perhaps that might be for next year. That is one of the key uncertainties around PPOs. We are producing a quantitative survey, and we are also looking at some work on what market solutions might look like, and what capital implications there might be for those. We are looking at capital solutions and we are trying to do something more on reinsurance pricing.

The Chair: We are now going to move on to our presenters. Keith Brown is senior claims analytics manager at Axa in London. Within Axa, he has worked on reserving and capital modelling in general insurance and on the pricing of unit-linked wealth products. His reserving experience on motor lines was immediately before his current role and included responsibility for Axa Insurance's PPO Reserving Framework. Keith has been a member of the PPO working party since 2013, leading the information paper and the index paper workstream. He is also a member of the measuring uncertainty qualitatively (GI Reserving Oversight Committee) working party.

His co-presenter is Peter Taylor. Peter has been a member of the PPO working party since 2015 . He has a broad range of experience across reserving, capital management, reinsurance and financial risk management from his 12 years working in Aviva's UK and Ireland general insurance and global head office function. He has just started a new role as the head of planning for Aviva's UK general insurance business following his 3-year stint as the head of reserving, where he had responsibility for first line reserving work for UK and Ireland's general insurance business, and also undertook Solvency II risk calibration work for reserving and underwriting related risks.

He was previously a member of the Institute's asbestos working party from 2007 to 2008, and he has presented at insurance industry events on asbestos-related claims, reinsurance counterparty risk and, of course, PPOs.

Mr K. S. Brown, F.I.A.: The definition of a PPO that we came up with is that it is a contingent, deferred, whole life, wage inflation linked, guaranteed, impaired life annuity where the identity of the annuitant and the size of the annual payments are unknown at the policy's inception.

That is quite a large definition. PPOs are clearly contingent on survival, either if they are a principal claimant or their dependants. They are generally deferred. We have had some feedback on that as the paper goes. But if you are reserving for future PPOs, there will be a deferral period (certainly at inception) of the policy. They are generally whole of life, but not always. Some heads 
of damage will cover essentially wages, which will terminate at retirement. They are wage inflation linked.

There is a guarantee to pay the annual amount. In some circumstances, that guarantee is more detailed. It could be guaranteeing to pay costs that the National Health Service (NHS) can reduce in the future.

Generally, PPOs are for impaired lives, although not always. Sometimes there is not enough information. We just do not know who the annuitant is at the beginning. I do not think that we would try and write this as a life risk at outset, but it is something as general insurers that we are faced with.

I think, talking this through, it has probably made it quite clear that that does not cover everything. We thought that we would probably need to move on slightly from a single statement towards an information paper that would essentially cover the topic in far more detail.

When we were discussing why to write the paper, we realised that there is a wide variety of methods in the market. That disturbed us slightly. Although it is quite useful to have a variety of methods, are they all correct? Are they all relevant? We produce quite a lot of output as a working party. There is a lot of work done on mortality. There was some work done looking at discount rates that people are using but there was nothing really that brought it all together.

As we were having these discussions, we became a bit concerned for our companies because clearly this is potentially a long-term capital risk because it is over a very long time horizon. Even if your capital is maintained, it is quite possible that companies will drift towards looking more and more like a life company as time goes on, and have they really thought about that? We were very concerned about our own companies and whether the risk was clearly understood.

We were quite concerned about ourselves because obviously we need, as a profession, to make sure that we keep on top of this risk, and it is something that we explore together.

As we were discussing this, the GI Board was considering whether some sort of guidance needed to be provided because it is an important area. As Peter mentioned, we did not feel as if we could do that. There is not really a framework for technical guidance and we would not be comfortable doing that.

What we came up with, is trying to collect the views of the working party, and others that we have sought outside, and bring that altogether in one place as a helpful handbook. The handbook is targeted at both people who have not seen PPOs before, and also experienced practitioners as almost a framework to go through to see whether they have considered all of the issues.

One of the key topics in the paper is the type of risk that is being covered. The life risk itself is unfamiliar but it is also unique. If we are trying to consider what life expectancy we are looking into, typically these will be people (if it is motor) who could have been hit by a car and have life-changing injuries. They could have fallen from a height in an employers liability (EL) or public liability (PL) claim. In that case, the injury is going to affect the rest of their lives.

It is possible that their life expectancy has changed. It is not guaranteed. It is quite possible that that has changed because they have had a fundamental change. 
We get information about that life expectancy in lump-sum settlement processes, so that gives us some information. But it is not the same as in life insurance where you might try and get everything done by an underwriter. It is not a standard part of the process at the moment. Even the flow of information is restricted.

If you are looking at PPOs, some people might not require very much care at all, which is what a PPO is to fund. If they have had a brain injury, their care maybe limited to making sure that they are generally all right. They might not have been physically affected. If they have been paralysed, then they might need constant round-the-clock 24-hour care.

It is a really wide range of impairment to life, and each claimant is unique and there is a very low number.

That brings us onto the key issue that has frustrated me when other people have checked some of my work from an external point of view, normally outside the area. They say, "Why do you not use a life table?". Probably it is quite clear to a lot of people in here that have dealt with PPOs that there is not a table for mortality for PPO claimants. Certainly, it is going to be highly challenging even in the fullness of time to create one with such a wide range.

If you look at brain injuries, you get a pocket of claimants that are affected to a small extent and then you get some who are severely affected. If you are looking at spinal payments, there is generally an effect on life expectancy; it seems unlikely you could have a simple PPO life table. You would at least in this case need a brain and spinal life table.

Another risk that is unique to PPOs is incredible inflation. I say "incredible" more from an actuarial viewpoint in modelling it. Most PPOs are linked to the Annual Survey of Hours and Earnings (ASHE). They are in subcategory 6115 , which is for care assistants and home carers earnings. In principle, this sounds a good idea to me because we are trying to change the level of payments in line with the amount that should be paid out for their care. Just from a common sense perspective, that sounds really good. If I am valuing a PPO, this sounds far less exciting because, to my knowledge, there are no investments that are widely available and deep and liquidly traded in the ASHE 6115 index. There might be some in Retail Price Index (RPI) out there but ASHE 6115 is not something that is widely available, to my knowledge.

So that leaves us with a bit of a conundrum of how to model this, especially considering that the assumption will be running over decades.

Just to keep reserving actuaries on their toes, not everyone has a link to ASHE 6115. Some people have seemingly a better link to RPI. Others are linked to all sorts of indices such as an overseas index. It just goes to show you what a challenge a reserving actuary can have.

Linking into inflation again, if you look at ASHE 6115 it does not look highly correlated to RPI. Colleagues in capital modelling look at that and are slightly anxious, they can see the negative correlation.

If you are looking into a bit more detail, you could look, for example, in the paper where we say you could also reference to interest rates.

You could look at RPI and look at how that compares to general wage inflation with the whole economy. Actuaries would generally look at how much above RPI wage inflation is worth. So you can see that that is not fully linked. It has slightly more of a pattern than what we were seeing before. 
If you think that you can find a pattern to the wage inflation for a whole economy, you can see that health and social workers in the average weekly earnings survey, and then ASHE 6115 does seem to correlate a little bit better but it is still not perfect. It is still quite noisy and still a risk that is very challenging to model.

Those are the really big risks that we cover in the paper. There are many more such as propensity which has been going up and down. That obviously will affect future settlements.

How much does it cost to handle these over decades, especially if there is outsourcing? The interest rate itself, although a technical point, does need to be considered. There is the operational risk. If this is a new area, have you all the controls in place? Are PPO valuations on manual spreadsheets or are you using a life valuation framework?

Court award inflation is another source. That is the actual level of inflation on the initial annual payment amount which may act independently from the ASHE 6115 inflation because of the influence of the judicial and settlement process and settlement. We have two sources of inflation for PPOs rather than normally one if you are looking at index-linked annuities in life.

Variation order is another one. Many PPOs have a clause whereby if a specific medical condition arises they can go back to court and essentially renegotiate the settlement amount. That is another risk that needs to be considered as are the additional credit risks and dependencies on reinsurers over the years.

Mr P. M. Taylor, F.I.A.: Moving on to the rest of the paper, following a thorough explanation of the risks, we move on to issues around the theme of reinsurance.

It is quite common that some elements of PPO risk are transferred to reinsurers, most commonly in the motor insurance space by excess of loss cover on individual claims. There are a number of different ways in which treaties are written. It is very important for an insurer to understand how its reinsurance arrangements have changed over time. There has been a trend for some reinsurers in the market who prefer to offer capitalised terms. This means that the arrangement with the reinsurer will be that you have effectively commute the PPO claim at the point of settlement for a lump sum, as opposed to a traditional arrangement whereby you are paying out $£ 100,000$ or $£ 200,000$ a year and only clawing back the money from the re-insurer as and when it becomes due.

Indexation produces another complexity. It is really important to make sure you understand how those arrangements might have changed over time or even within an individual year; that you might have a panel of reinsurers, some of whom are on a traditional, and others capitalised, basis.

Obviously, the cashflows, especially on a traditional basis, are extremely long duration. That has an obvious problem of credit risk, considering the likely credit rating of a reinsurer 50 years out. How likely is it that it will definitely still be here? It may well be very different to the credit rating that they have today or their credit worthiness at the moment.

The other factor that can come with that is that if you have a company which has particularly high excesses, it might be that those traditional recoveries do not kick in at the point of settlement 5 years out. They might not kick in for 30 or 40 years, contingent on the survival of the claimant. 
That produces operational issues around making sure that you have the systems and capability to be able to trigger those recoveries when they are due and not let the reinsurers off the hook.

Moving on to the key themes in the chapters in the paper, the first one on which we have a section is about data and assumptions.

A key factor with PPOs is that your data is probably not coming straight off-the-shelf out of your existing IT framework. You probably have to spend some time investing in how you collate the really important data that underpins the PPO valuation.

So to the court orders themselves; the information that tells you what index has been applied to this particular claim. How do the step payments work? Information around medical opinions to help you value what the impairment might be. That will tell you things like: when are the payments going to start; and how they are going to work. Is there a variation order? You really need to have a good relationship with your claims department to make sure that you are capturing that in a robust way going forward, and making sure that that data is available to your actuarial children and actuarial grandchildren who will still be valuing these liabilities 70 or 80 years in the future.

You are then going to have to start setting assumptions. This is the really tricky judgemental bit. There are a number of areas, as Keith has touched on, that are very unusual and very poorly established in terms of the actuarial literature.

The inflation rate you are applying to future payments is absolutely key here. How on earth are you going to project that over the next 90 years? There is some historical data, ASHE 6115, for about 12 or 13 years. You are trying to project it out for the next 90 years. What sort of macroeconomic assumptions are you making about how the wages of the general population are going to develop and how the wages of care assistants specifically are going to develop? It is hard enough trying to project that for next year, let alone 90 years on in the future.

You are then likely to be (in most reporting bases) discounting liabilities. What investment return assumptions should you use? Is that prescribed? In some reporting bases it is prescribed, in other places it is really a matter of judgement.

How do you link that to inflation to make sure that you have a coherent set of economic assumptions that are acting consistently?

You then have to come up with the technical method for how you are going to allow for medical opinions and their reduction to life expectancy.

There are a number of detailed technical methods that you could adopt and they are explored in the paper. They can make a material difference to the valuation of your liabilities.

How are you going to project the propensity for your firm for the liabilities that you are valuing, either as a consultant or working with an insurer or reinsurer? Propensity can be influenced by a number of factors: what the firm is doing as a claims management strategy; and the type of policies that they have written. It can also be influenced by the economic scenarios that you are outlining. One of the tensions can be, if economic conditions have high levels of inflation but low levels of investment return, does that make taking a lump sum less attractive for the client? 
Focussing on valuation from a reserving perspective, we have explored in the paper a number of principles that we think are important. This may sound obvious but it is quite important: triangles do not work with PPOs. That is a recommendation we felt fairly comfortable in making, even notwithstanding it is not guidance.

It is really important when you are undertaking a reserving exercise, to make sure that you fully understand what your claims handlers are putting in their case estimates, and what your traditional reserving methods for the claim are already factoring in, so that you do not double count risks that are already captured within those processes.

Cashflow models are really important if you have a material exposure. That really allows you to understand the impact of the investment return and inflation assumptions that you have adopted.

Do not forget about reinsurance. Given how much expert judgement is going into all your assumptions, stress and scenario testing is really important to help tease out the range of best estimates so that you can help articulate to your senior management how different the reserve best estimate might be, just from some small tweaks to the methodology or assumptions you are adopting in your model.

One of the ways to help you track that over time (and this does not come together immediately but is very valuable over a longer period) is to set up an actual versus expected experience process. It is very important to make sure you track how well your assumptions are performing against actuals. For propensity, you can quite easily set up actual versus expected experience, but it is not so valuable yet for mortality. Again, over time, that will help us give a feel for the bias inherent, or otherwise, in mortality estimates.

If you thought that was hard, you then have to think about the range of possible outcomes. It may be from an internal management perspective; it may be from a regulatory perspective. It is really tricky to extend those estimates out to the full range of possible outcomes.

There is some discussion in the paper about this aspect but I think that there are a number of reservations about whether the Standard Formula is appropriate. We have discussed some of the technical challenges that presents.

We think that one the sensible ways to think about your model design is to think about how you can link it to your reserving models. What are the material risks to the firm that you are valuing? There is not a one-size-fits-all approach here because of the extent to which reinsurance is important or not important to different firms. Balancing parsimony and sophistication is really important. You can go completely to town and get a model that will be unworkable and unusable, or you can get something that is too simplistic and misses material risks.

Calibration, as we discussed, is very challenging because of the level of expert judgement. There is the potential for correlation between numbers of variables and that makes validation incredibly important with a PPO model. You cannot just rely on saying: "I have managed to calibrate all my things and prove with the statistical data that it is absolutely perfect" because there just is not the data out there. You have to really think hard about validation activity.

Use stress and scenario testing, working with others in the firm to understand the possible outcomes around PPOs and really test whether your model is capturing those outcomes. Over time, back 
testing, stability testing and peer review of the model. That might be in a formal context, independent model validation, or it might just be going and speaking to other actuaries in your firm and other experts to help understand whether you really have a sensible model.

A healthy dose of common sense cannot hurt as well. Is your model telling you that you are getting adverse outcomes in the scenarios when your stochastic variables are coming out with an adverse outcome?

Finally, the last section in the paper is on pricing pointers. Pricing actuaries, probably, have spent less time than reserving and capital actuaries thinking about PPOs but it is still important for them. It would be fair to say that there is probably not enough data at the moment to factor in PPO rating factors specifically. We suggest the main objective at the moment is to make sure that there is clarity on the extent to which PPOs influence the costs that need to be loaded into large claims. How many of your large claims are going to settle as a PPO? What is the additional cost? By that we mean obviously the best estimate cost. A PPO, in general, on current economic assumptions, will tend to be more expensive than a lump sum, materially so, and there is a huge range of possible outcomes, so the capital loading that you might need in your pricing could be very significant.

In determining those uplifts, you need to be cognisant of what economic assumptions you are going to use, how your reinsurance works, what that level of additional capital should be, what basis you want to use and then also think about whether there is any underwriting information. A lot of this though does boil down to, are there factors outside the propensity for large claims that increase the propensity for certain types of claim to trigger a PPO?

I want to close on the professionalism aspect that we have to bear in mind. PPOs are there to support individuals who have absolutely fundamentally life-changing injuries and need care for the rest of their lives and need insurers to be providing those funds over their lifetime. You need to keep that issue in mind when you are dealing with stakeholders both within your firm, outside your firm and how that influences what you are doing as an actuary valuing PPOs.

To summarise, the main recommendation that we have in the paper is that it is very important for actuarial practitioners to increase their knowledge of PPOs. This paper, we hope, is helpful to them in doing that. PPOs are not a static area of research. The PPO working party is a continuing working party looking at a number of areas. We think you need bespoke PPO models. They should be cashflow based and they need to cover specific PPO risks. The risks are material and uncertain. You need to communicate those risks to senior management effectively. You need to keep up-to-date with what is going on in the external environment, and you need to work not in a silo but with others in the profession. Life actuaries might have something to tell us about longevity modelling. Our legal friends, claims handlers, investment professionals, a number of other specialists, can help you broaden your knowledge around PPOs.

Back to the professionalism point, you need not to forget the requirements of the actuaries' code and the other professional standards, including but not limited to the TAS.

Mr Saunders: This is a new risk for GI actuaries and is something that, historically, they have not been used to doing. It is something that we need to continue to push, we need to continue to make people aware of developments and continue to make sure that, as a profession, we are looking after our stakeholders and we are serving the public interest. 
In terms of assumptions, there are a number of assumptions we are going to need as we go forward. Mortality is still uncertain. We are trying to do something on that in the working party. Inflation is clearly uncertain. We have seen in the past ASHE reduced. There is an argument that ASHE reduced because of migration. Now there is a question of what does Brexit mean for that. If ASHE has reduced as a consequence of migration, how will that change going forward?

On the assumption of how many PPOs there are going to be, we know the Ogden discount rate consultation is ongoing. We do not know when that is going to finish. Perhaps in the near future the government may not be that interested in the consultation. In the short-term, they may have other things on their mind. How long that is going to take will be a key thought, possibly more for reserving actuaries than for pricing actuaries who are probably thinking about how things might change in a settlement year.

With these new risks, there is an increasing requirement to communicate the uncertainty to boards. In GI, we are not as responsible as those in life and in health for the ultimate reserves on the balance sheet. It is absolutely vital that we make sure that we communicate not only what assumptions we have made, but what the impact of other assumptions would be.

We talked about the fact that triangles do not work when you are trying to come up with reserves because even if you had a triangle of 80 years, the changes in mortality in the population and legal environment over that time would render those triangles obsolete without significant adjustment.

From the information paper, we are interested in what do people think is the biggest risk that PPOs pose? How can actuarial practitioners increase their knowledge on PPOs and the issues surrounding them? Hopefully, through their continued existence as a working party? Will life tables for PPO claimants ever exist? We are trying to do some work on that and we are trying to get some use of the research projects that the IFoA has in place. Do people know what their firms' approach to PPOs is? What should people be doing to gain a better understanding? What do people think in terms of how people should set the main assumptions? Is there value in stochastic models for PPOs? How do we expect capital modelling in the PPO liabilities to develop in the future? And the big question for me there was Brexit. Even if we do exit, then we have to have equivalence anyway, so we are likely to have a situation where it might be similar. I guess that is more for the PRA to ultimately comment on the position. Even beyond that, how does your capital modelling compare to your risk mitigation? Solvency II would require us to do something about the likelihood of failure in a 1-year time horizon. How does that compare with our actuarial responsibilities, making sure that a company can meet the liabilities as they fall due?

How will PPOs be priced? That is as important for insurers as it is for reinsurers. Will rating factors be used? How should companies be approaching rating factors? Will we ever get enough information to do that?

In terms of PPOs more generally, questions we are raising: what is the most appropriate asset liability matching policy for a firm? How much should statutory regulatory accounting requirements affect that decision or should a company really be thinking more about how they want to make sure that they are dealing with PPOs in the correct way?

Do people think that companies are adequately reserved? Is the profession doing enough to ensure that companies are being adequately reserved because we do not want a situation again where the profession could be criticised for not dealing with these liabilities for their firms. 
How will people think poor lump sums might affect PPO propensities? Should claims be indexed using ASHE 6115? There is still a basis risk to claimants within ASHE 6115. We have seen that has gone down, but I do not think that it is likely that the care providers will have passed that implied saving onto claimants.

What is fairer for the claimant, a PPO or a lump sum?

Are there things that we can learn from other jurisdictions? Here I would like to highlight that the working party is currently working on creating a mini website where we have looked at other jurisdictions. We will perhaps have more information about that at General Insurance Research Organising Committee.

Do people think the actuarial qualification should have more information on PPOs or do they think that the requirements of how to value a life risk in some of the Core Technical subjects are sufficient? What should happen if one or more insurers cannot meet their obligations?

Finally, I will talk about a question that I commonly get asked. People ask what I would prefer if I were ever injured. Would I prefer a PPO or would I prefer a lump sum? It is clear, I do not want a PPO but I do not want a lump sum either. To me, I do not think that even one of those accurately compensates an injured claimant for the financial loss that they suffer as result of the PPO. There are other places and other jurisdictions, where the value of compensation is the value of care that the person needs, not a value of care at some point in time indexed in the future.

There is a question of that in terms of public interest. Clearly in the interests of the injured claimant, the change of compensation mechanism would be better. But is that necessarily the right question for society, and what does society want to do?

Does society want for a claimant to have full compensation? Are they happy for that claimant to have some basis risk? Are we thinking about potentially a higher compensation, which would be expected to have implications on the prices of insurance companies. Or do people want to be comfortable with the amount of insurance that they pay?

The Chair: Thank you, Peter. Now we are going to move on to the discussion.

Mr M. G. White, F.I.A. (opening the discussion): Where there is a PPO, there is often not just a PPO, there is often more than that. It would be good to show a claims cost breakdown for a large claim. In practice, there can be lump sums required to adapt somebody's house by other specialist equipment, and as well as a PPO, the non-PPO elements can be quite significant. That angle does not come out within the paper, and it is quite a challenge when reserving, to think that if there is a PPO, versus not a PPO, what difference would it make.

Related to that, you mentioned the Ogden factors. The Ogden factors are egregiously non-generous to beneficiaries at the moment. I cannot see how we can stay like that. Currently, everything is priced on the basis of continuation of the status quo. So some nasty shocks might happen at some point.

Mr N. B. Odozi, F.I.A.: I am wondering why the identity and the amounts of payments are not known at inception, being a non-GI actuary. I think you mentioned that the amount of payments might be linked to how much care people need. 
Mr Saunders: At the inception of the contract, you are not selling a life policy. At the inception of the contract you are selling a motor policy so you have no idea at that point whether you will get a loss. You do not know whether you will get a claim. Even if you do hit someone, you do not know whom you are going to hit. You do not know how damaged they are going to be and the level of care that they are going to require. Because of that, at the inception of the contract, yes, you cannot know the annual amount, which is clearly, compared to life insurance, very different.

Mr Brown: Even if it were EL or PL cover in general insurance, the cover will be for a third party. They will be unknown at the point the contract is sold.

Mr Saunders: We have seen massive variability in terms of annual payments. We have seen payments as low as $£ 20,000$ a year up to payments of $£ 450,000$ a year, increasing with inflation, to 6 year olds. Volatility on some of those is enormous.

Mr N. A. D. Hyatt, F.I.A.: I am puzzled why anybody would seek to value PPOs on a deterministic basis rather than stochastic. Everybody, I think, is fully aware of what has happened previously when we have attempted to assign the values to some liabilities using a deterministic basis. The equitable is the obvious example.

The other question that I would ask is when you are referring to mortality tables there is the traumatic brain injuries study from the US, and I am curious as to why you believe that would not be appropriate for looking at PPOs.

Mr Saunders: In terms of deterministic versus stochastic, it comes down to what you are trying to do. If I was pricing a reinsurance contract, I would probably be more inclined to use a stochastic model because then I obtain the correct probability of those losses exceeding the reinsurance deductible and then that works better.

However, if I were valuing from a gross basis, a direct insurer's reserves, then I do not think the difference between the value on a stochastic basis versus a deterministic basis (assuming you still use a life table with probabilities applied to each year) is significantly different.

Mr Hyatt: I was thinking more in terms of the variability in the value of the assets and the value of the liabilities. It is an old cliche that the value of a general insurance company is the difference of two very big numbers. If one number goes up and one number goes down, you can see a great big strain on it.

I find difficulty stripping capital management from reserving as I think they should both be looking at the same features.

Mr Saunders: If you were trying to come up with a point estimate then a deterministic versus a stochastic should give a similar answer. I will agree, that if you are required to, and you should be wanting to produce a range of outcomes, you would have to use a stochastic model to the degree to which the actuary felt they were happy with the parameterisation in the stochastic model and the volatility of their assumptions over inflation, and their assumptions over the correlation between inflation on the one hand and the investment income on the other.

Is it possible to be comfortable in the parameterisation of a correlation between ASHE and investment income? 
Mr Hyatt: I accept that. I think you do need to consider the problem. If you were a shareholder in a company, you would be expecting the actuaries employed by the company to be considering those questions.

Mr Saunders: Given the uncertainty under parameterisation, are you going adequately to be able to communicate the subjectivity around the parameterisation to the degree that those making the decisions over the reserve levels understand it, or are you better to say if inflation is $5 \%$ more or $5 \%$ less, then the impact is this, and to give more of a scenario approach rather than a stochastic approach.

Mr Hyatt: I think both approaches are valuable. I think, when doing reserves, we should be looking at the impact when inflation is moved by XYZ, then the impact on the results would be whatever, so people could see how the company would move.

Mr Taylor: I think we do agree with that. I think we have discussion in the reserving sections about the importance of that kind of stress and scenario testing. We would absolutely agree with the importance of understanding the impact on both assets and liabilities of some of these assumptions. Your capital model cannot sit in a bubble just valuing the liabilities; you have to consider the impact on assets, which may well move not necessarily perfectly but at least in compensatory directions with the liabilities. I think we recognise the importance of having that coherence in your modelling, particularly in the capital space. We do touch on that in the detail in the paper. I think stochastic reserving models per se is hard for the reasons Peter has been talking about, but I think we do recognise it is definitely there. It is something that practitioners should be aware of and consider.

Mr Saunders: We will certainly have a look and think in terms of whether we want to draw something out on that in more detail in the report.

As for the point on brain injuries, there is always the question of whether something in the States is necessarily relevant and whether you can necessarily pick out the same level of injury, the same types of injury, and if it is a brain injury caused by a motor accident versus a brain injury caused by, say, obstetrics, then you might have very different levels of impairment and levels of survival.

Mr Brown: There will be a different attitude in society (across the jurisdictions) as to what level of care is offered which would affect the survival. If you mean the Strauss studies, they often do creep into general insurance reserving because they will be considered in the settlement process on a lumpsum basis, which then often informs the PPO life expectancies. Previously, we were aware on an individual basis, you could come up with a medical recommendation from different factors. It is how much that would be relevant to the UK life risk. I have had the challenge before of looking at a foreign national. In this case, there was a very different life expectancy to a UK national. Even doing that was a challenge and it drew out some interesting points. Certainly within our mortality workstreams, we have looked at New Zealand experience where, in a particular year I was looking at, there was a really high accident bump for females due to an earthquake. It just shows you how detailed it can become and how important it is not to generalise too much.

Mr Saunders: One challenge looking across jurisdictions is that as the claimant has the option of taking a PPO or not, you can get a selection element. You then need to consider whether there is a select element to PPOs, and whether that potentially would be relevant for the data that forms part of the traumatic brain injuries study. 
Dr P. J. C. Chappell, F.I.A.: The crude death rate in the UK is just over $1 \%$ per annum. If you had a steady-state situation, you would need about 100 years for that to become steady state from where it is now.

If PPO recipients die at a slightly higher rate than that, you are still looking at maybe 50-100 years before it becomes steady. That illustrates the long-term nature of this topic. The liabilities will go up and up until some kind of steady state is achieved.

Quite a number of years ago in Australia, there was a paper or two by Walsh and Yeo. They have looked at impaired lives for paraplegics/tetraplegics. It is very, very crude but I think there was a multiplier for the mortality up to age 70 and then it dropped back to 1 . I did some calculations many years ago, even at five times the normal mortality, the actual life expectancy does not drop that much. So, although it is quite uncertain in terms of life expectancy, if you obtain a professional opinion, it is probably as good as anything else to use a multiple of normal motality, or an addition to the age.

The third thing is indemnity. It is an indemnity against injuring other people. It may be that pensioners injure other pensioners more often; it may be that young men injure young men more often. It may be that 30-year-old women drive into other people's children when dropping off their children to school but there is not going to be evidence enough in the data for there ever to be any real underwriting consequences. I cannot see there being enough data which is clear enough, to identify groups that injure other groups more often than randomly.

Finally, some years ago, I had to give evidence in a court case which involved some work I had done 10 years before. The key thing is to document what you do to make sure that you have tested what you are going to do with other people, gather opinions and make sure you document them thoroughly, because in the end, if it is not documented, there is no evidence that you have done it. It is really key when you are deciding things like this and, as actuaries, we have to put our names to these things. We have to make sure that we really can justify, not just to ourselves but other people, the decisions that we have made, the selections we have made, the assumptions we have made.

Mr Taylor: One of our observations was that the absolute number of PPOs that firms will have, even in 50 years' time, might be quite small. So it is easy to forget, if you are a life actuary writing annuities that the number of lives you have is enormous and therefore a life table is smoothing out all the specific risk. The problem for most, even large GI firms, is the number of claims is currently so small but you are looking at aggregate mortality experience the wrong way. The mortality experience for the specific claims that you are exposed to is important and the variability of opinions given by medical practitioners is wide for claimants. Any individual portfolio may have a specific skew towards very heavily impaired or very unimpaired claims. I think that specific risk is something that is quite easy to forget when you start applying life techniques when typical life insurers do not have to really worry about that sort of specific risk. I think that is one of the things to bear in mind before getting too bogged down in "can I come up with a whizzy life table?".

Question from a member of the audience: If we go back to the case of life annuities or pension annuities, there is obviously a very large number of annuities out there which are linked to RPI, Limited Price Indexation or perhaps Consumer Price Index (CPI). Correspondingly, you have also a very large market for inflation in gilts, and nominal gilts, from which one could derive an inflation assumption. You also have an inflation swap market. 
Typically, the standard process there would be to take a market implied assumption for RPI and use that to project with. If you have CPI, then perhaps one approach, because there is not such a market for CPI, would be to model the basis between CPI, as it is a different form of inflation, and RPI. What are your thoughts on potentially applying that same technique to PPOs? Projecting using the RPI swap market, as a base case assumption for this is what RPI will be. On top of that, thinking about what is the ASHE versus RPI spread likely to be? Perhaps that is easier to make assumptions about than trying to make econometric assumptions about what is going to happen to inflation out for 90 years.

Mr Taylor: We would agree that that is definitely one of the plausible methods, but not the only method, for setting assumptions.

Mr Saunders: The biggest challenge at the moment is we have a much smaller observation window for ASHE than we do for CPI. So doing a really good estimate of what is the correlation between RPI and ASHE is very difficult given that we had implementation of the minimum wage plus the biggest financial crisis in our living memory in that period. It is definitely a valid approach.

Comment from a member of the audience: It seems it might be easier to project using that basis because they are both forms of inflation, rather than to try to project inflation from the bottom up, as it were, over that period.

Mr Brown: I think it is an important point and I think this highlights where, even if you use stochastic modelling, you potentially need a deterministic model to sense check it because that is a valid approach to use. If you are thinking of PPOs, and therefore care workers, we do not know where the economy is going to go, especially after the recent changes. So, if we have an ageing economy, the inflation in that sector could rise considerably compared to RPI.

In that case, would we have enough reserves? You will not necessarily see that in the market curves. It might be averaged in, but in that specific scenario, what would the company have to do over that time period?

I think it is important, whatever method we use, to have a healthy dose of common sense and explore what the actual risk could be.

Mr A. R. Lee, F.I.A.: You mentioned talking to interested parties, claims handlers, lawyers and so on. You did not mention there the claimants and the courts. I wonder whether there is a case here for us, as a profession, to give some sort of impartial document, maybe off the back of what you are producing here, to inform people in everyday language about how PPOs work. That might be useful in future for people to make a decision about whether they want to take a PPO or a lump sum?

Mr Saunders: On whether the profession would want to do something that would be given to claimants, I see the value in that. I would probably leave it for others to decide whether to push that forward or not.

But if anyone wants information about it, then include the working party, since this is an area where we could provide some insight. 
Mr White: On the question of future inflation, I think using the lessons of the old world of pensions, the issue is not just inflation. It is what is your asset strategy going to be? Given that asset strategy, what do you think your real long-term return will be?

If you make an assumption about a certain level of real long-term return and you reserve on that basis, then, however, you place the value on your assets (you may use different concepts to market value to do this), if you prove to have been not prudent enough, and your company has long since gone into run off, then you are very, very bust.

The only way for an institution providing benefits of this sort of length to survive, is to look at its asset strategy and then choose an assumption set that is very prudent, and for that to be possible, there may be some interesting questions to be asked about accounting, solvency and tax.

Mr Hyatt: You have the obvious issue of affordability. It is all very laudable. It is the amount of capital that would need to be tied up with the implication for the pricing of the insurance and the reinsurance. What would that do to pricing?

Mr Saunders: The question comes down to really how much capital should you hold and how should you think about your capital? Should you be measuring your capital on a 1-year time horizon where you are potentially asking shareholders, "If anything goes wrong, we will be able to recapitalise by asking you to put in more money". So by looking at an ultimate view you would be saying to shareholders "this is the amount of money that we need to look after these claims". We should be looking to manage our expectations of the liability over a period of time or shall we be saying to shareholders this is the capital you need this year. There is every chance that that capital might need to be increased in future years because we are thinking only about what might happen this year, not how much capital the shareholders might have to put in, in the future.

Surely, you have a duty to your shareholders to highlight how much capital that might need to be put up in the future, if inflation assumptions or investment return assumptions are different from what you might be saying.

Mr Hyatt: I thought Martin's point was that when setting the initial pricings and the capital to be set aside, the mortality and the investment assumptions should be very conservative. That is all very laudable to ensure that companies are going to be trading.

What implication does that have on pricing and people's ability to afford to buy insurance with the amount young people pay for insurance these days. If you started insisting that companies need to hold two or three times as much capital as they do at the moment to make sure that they would not go bust in the event of PPO claims, what would it add to the pricing of their premiums?

Mr Saunders: If we think a company should hold that level, yes, clearly it would increase the prices. But if that is the right answer, then we should not be afraid of saying that, if that is the best way of mitigating the risks of managing a company. Why should we be worried about saying that just because it will put up prices (if that is the real cost of the liabilities)? I do not think Martin used the word "conservative". I think I recall him using the word "prudence" rather than "conservative". I think there is a difference potentially between the word "conservative" and "prudence". 
Neither would you want to use assumptions that are so aggressive that it is unrealistic that they could be achievable.

Mr Taylor: It does, nonetheless, throw up quite an interesting ethical question around if you are happy to pay extra for the insurance as a group and pool that risk or would you rather people set assumptions that were more best estimate but there is more risk involved for the shareholders? Again, it is almost like a risk-sharing exercise.

If there was a default, who would have to bear that cost and could they?

Mr White: PPOs are a significant part in the long run of an insurance company's balance sheet. But they are not the largest part of all claim costs. What really drives insurance premiums is the competitive nature of the market and quite often the suicidal nature of some of the insurers in it.

Arguably, I think the public has done rather well with this insurance because every now and then, an insurer goes mad and uses its capital, having basically donated it to the policyholders.

The Chair: So there are some interesting ethical points there. I am wondering where our responsibility lies. What you have said, is that essentially people have benefited from having lower premiums. Is that because they are ignorant of the risk that they are running and the fact that some people are going to have PPOs that will not get paid?

Mr Saunders: I think the PPO will get paid because a PPO is protected by the Financial Services Compensation Scheme (FSCS). But it will be incumbent on the FSCS being around in the future and not going bust in itself. Also, that cost to the FSCS will have to be borne by the rest of the industry, so we are potentially asking future generations to fund current PPO liabilities in the event of a company collapsing and the FSCS needing to fund those liabilities going forward.

Mr Taylor: We should note that that is no different from the approach that the government are taking with NHS medical malpractice claims. They are similarly putting that out to the long grass, and effectively taxpayers are taking that risk.

Mr L. E. Proctor, F.I.A.: You showed that there was not a strong correlation between RPI versus ASHE. Have you done further analysis to suggest comparing other indices with a strong correlation somewhere?

I have heard a lot of rumours that there might be a secondary market emerging. I have not seen any evidence yet. Do you think this is something you see as likely to emerge?

Mr Saunders: I have not seen anything that would imply a secondary market emerging. Every time I have asked anyone about it, internal or external, in terms of anyone likely to provide any hedging, they have said no.

I have seen people want to try to create solutions, more like reinsurance solutions or pooling solutions where you could pass PPOs in whole into some sort of arrangement. I have not seen anyone just try to pass the ASHE risk off.

I certainly have not seen anyone want to take the ASHE risk. 
Mr Brown: I think that is the key point. For me, we have seen people attempting, potentially, to pass off the ASHE risk. You have to find the counterparty to accept that risk, and that is something I have not seen a lot of.

Mr Taylor: We have looked at other indices. We do discuss in the paper the extent to which you can look at alternative data sources. ASHE only runs for a limited period of time, but it is possible to obtain data going back for a much longer time on wages more generically and prices more generically.

You do, quite quickly, run into questions of credibility, accuracy and relevance of some of that data, but it does not mean that it does not exist. One of the reviewers of the paper noted that the Wealth of Nations by Adam Smith contains such analysis, and that is nearly 300 years old.

There is information out there and we have pointed out that that kind of research is possible, but it comes with a lot of health warnings around the data sources that are available and the relevance that they have to the future and the current economic environment.

Mr Saunders: If somebody wants to do it on behalf of the working party, I am happy to create a role for someone to come and investigate it.

The Chair: I should just like to say thank you to the authors of the paper, to Peter (Saunders) for opening and closing the argument and to all of you for participating in what has been a very active discussion. 